\title{
A fungus among us: broad patterns of endophyte distribution in the grasses
}

\author{
Jennifer A. Rudgers, ${ }^{1,4}$ Michelle E. Afrhami, ${ }^{1,2}$ Megan A. Rúa, ${ }^{1,3}$ Andrew J. Davitt, ${ }^{1}$ Samantha Hammer, ${ }^{1}$ \\ ANd VAlérie M. Huguet ${ }^{1}$ \\ ${ }^{1}$ Department of Ecology and Evolutionary Biology, Rice University, 6100 Main Street, Houston, Texas 77005 USA \\ ${ }^{2}$ Section of Evolution and Ecology, University of California, One Shields Avenue, 2320 Storer Hall, \\ Davis, California 95616 USA \\ ${ }^{3}$ Curriculum in Ecology, University of North Carolina, 217 Miller Hall, CB\#3275, \\ Chapel Hill, North Carolina 27599-3275 USA
}

\begin{abstract}
Plant-associated microbes have been increasingly recognized for influencing host populations, plant communities, and even herbivores and predators. Thus, understanding factors that affect the distribution and abundance of microbial symbioses may be important for predicting the ecological dynamics of communities. Using endophytic fungi-grass symbioses, we explored how intrinsic traits of the symbiosis, specifically transmission mode, may influence symbiont frequencies in host populations. Combining published literature with new field surveys, we compared Epichloë endophytes, which had mixed horizontal and vertical transmission, with Neotyphodium endophytes, which were exclusively vertically transmitted from host plants to seeds. Exclusively vertical transmission should select against pathogenicity because symbionts depend entirely on hosts for reproduction. Across 118 host species, we found that Neotyphodium hosts had 40-130\% higher symbiont frequencies than Epichloë hosts. In field surveys, endophyte frequency was positively correlated with the local density of hosts, but only for Epichloë, suggesting that contagiously spread Epichloë may attain higher frequencies when hosts are more abundant. Epichlö̈ endophytes were also more likely than Neotyphodium to have imperfect vertical transmission; thus, hosts may reduce the transmission of more pathogenic symbionts to seeds. Results are consistent with the conclusion that the evolutionary transition to exclusively vertical transmission can alter patterns of symbiont frequency in nature.
\end{abstract}

Key words: endophytic fungi-grass symbioses; Epichloë spp.; Neotyphodium spp.; plant-microbe; Poaceae; symbiosis; vertical transmission.

\section{INTRODUCTION}

Plant-associated microbes are increasingly recognized for their potential to affect host populations, plant communities, and even herbivores and predators (van der Heijden et al. 1998, Omacini et al. 2001, Gehring and Whitham 2002, Klironomos 2002, Cahill et al. 2008). Most plants associate with microbial symbionts, including mycorrhizal fungi, nitrogen-fixing bacteria, and fungal endophytes (Smith and Read 1997, Bacon and White 2000). Thus, understanding factors that affect the frequency of microbial symbioses in nature may be important for predicting the ecological dynamics of terrestrial communities. Currently, much less is known about the biology of plant-microbe interactions relative to plant interactions with macro-organisms, such as herbivores or pollinators, particularly in natural ecosystems.

Here we focus on understanding factors that may regulate the distribution and abundance of symbionts.

Manuscript received 18 January 2008; revised 22 July 2008; accepted 5 September 2008. Corresponding Editor: J. N. Klironomos.

${ }^{4}$ E-mail: jrudgers@rice.edu
Prior research has revealed that both abiotic and biotic factors can affect the costs and benefits of symbiosis, potentially altering symbiont abundance (e.g., Oliver et al. 2008). For example, greater nutrient availability in the soil can reduce the frequency of colonization by mycorrhizal fungi that enhance nutrient uptake by plant roots (Johnson et al. 1997). Similarly, exposure to herbivores can increase the frequency of endosymbiotic fungi that confer herbivore resistance to host grasses, relative to populations protected from herbivory (Clay et al. 2005). In addition to these external factors, traits intrinsic to the symbiosis, such as the mode of transmission, may affect the frequency of symbiosis. Specifically, in a vertical transmission mode, symbionts are inherited by host offspring, whereas horizontal transmission involves the contagious spread of symbionts. Exclusively vertical transmission should select against pathogenic symbionts because the symbionts depend entirely on hosts for their own reproduction (Fine 1975, Ewald 1987, Gundel et al. 2008). This evolutionary transition toward mutualism may drive the specialization of hosts on particular symbionts and also increase symbiont frequencies in host populations (Werren and O’Neill 1997, Douglas 1998). 
We examined patterns of endophyte frequency for systemic fungal endophytes that varied in their mode of transmission. These endophytes associate with the aboveground tissues of an estimated $20-30 \%$ of graminoid species (Leuchtmann 1992) and are concentrated in the Pooideae subfamily of grasses, which includes $\sim 3300$ species (one-third of the family Poaceae). Two systemic endophyte genera are common: Epichloë species that range from exclusively horizontal transmission to mixed horizontal and vertical transmission (Clay and Schardl 2002, Schardl et al. 2004) and Neotyphodium species, asexual anamorphs of Epichloë that apparently lack mechanisms of horizontal transmission (Selosse and Schardl 2007). During horizontal transmission, Epichloë form sexual structures known as stromata on all or a subset of host tillers; tillers with stromata typically do not produce inflorescences. In some cases, Epichloë and Neotyphodium endophytes benefit hosts, even endophytes that form stromata (e.g., Pan and Clay 2002, Gonthier et al. 2008). Documented benefits include increased resistance to herbivores via the production of fungal alkaloids (Muller and Krauss 2005, Rudgers and Clay 2007) as well as enhanced drought tolerance, plant vigor, and nutrient content (Malinowski et al. 2005, Kannadan and Rudgers 2008, Rudgers and Swafford 2009). However, like many symbioses, costs and benefits can be context dependent, and outcomes may vary from mutualism to parasitism (Faeth and Sullivan 2003, Saikkonen et al. 2006).

Grass-endophyte associations may influence the ecology of many ecosystems. The grass family consists of $\sim 10000$ species, many of which are ecologically and economically important (Barker et al. 2001). Grasses and grasslands cover more than one-fifth of land area on Earth (Shantz 1954) and have a long and pivotal history in ecological research (e.g., Tilman et al. 1996). Grasses are commonly used in ecological studies without regard to their endophyte status (Rudgers et al. 2004). Although much of the current understanding of grassendophyte ecology comes from just a few grass species (Saikkonen et al. 2006), the potential exists for endophytes to have large ecological impacts. For example, in the United States, endophyte presence in the nonnative grass, Lolium arundinaceum, can increase the success of host invasion, reduce surrounding plant diversity, slow plant succession, and reduce the abundance and diversity of associated arthropods (Clay and Holah 1999, Rudgers and Clay 2007, 2008, Rudgers et al. 2007). Thus, understanding factors that affect endophyte frequencies in nature may be important for predicting ecological dynamics, particularly for grassdominated communities.

We combined new data from a broad field survey with data from the published literature to explore four questions regarding correlates of endophyte frequency (i.e., the proportion of plants with a symbiont). By compiling the most comprehensive survey to date on endophyte distribution in the grasses, we hope to provide a useful compendium for ecologists, increase the recognition of endophytes in ecological research, and spark new questions for future study.

1) Are endophyte frequencies greater for asexual Neotyphodium than for contagious Epichloë? Neotyphodium endophytes may occur at higher frequencies in natural grass populations if they are less parasitic/more beneficial to hosts than Epichloë species (see also, Leuchtmann and Clay 1989).

2) Is endophyte loss due to imperfect vertical transmission greater for Epichloë than for Neotyphodium? Imperfect vertical transmission of symbionts to offspring provides one mechanism to maintain variation in symbiont frequency (Ravel et al. 1997, Afkhami and Rudgers 2008). If plants can control vertical transmission, then hosts of Epichlö̈, which can prevent inflorescence production, may exhibit greater endophyte loss than hosts of Neotyphodium, which should be selected for lower pathogenicity. However, at least some asexual Neotyphodium may arise from Epichloë species following host switches. These "trapped" symbionts may survive in the new host, but be unable to produce the sexual, contagious stage. Thus, some Neotyphodium symbioses may be maladapted, and seed transmission may not only be less than $100 \%$, but actually declining in unstable associations.

3) Is variation in endophyte frequency greater among species than among populations within species, and does the amount of variation differ between endophyte genera? Large variation in endophyte frequency within species could suggest that benefits are commonly context-dependent or could also result from high levels of imperfect vertical transmission (Gundel et al. 2008). Neotyphodium hosts may exhibit greater within-species variation than Epichlö hosts because populations founded by endophyte-free plants cannot become contagiously infected.

4) Does endophyte frequency correlate positively with host plant density? Across host species, a positive correlation between endophyte frequency and host density would be consistent with the hypothesis that endophyte symbiosis enhances host abundance. If endophyte benefits indeed underlie this positive relationship, hosts of asexual Neotyphodium should exhibit a stronger correlation than hosts of Epichloë. An alternative hypothesis is that, regardless of their effects on hosts, Epichloë endophytes attain higher frequencies on hosts that are locally abundant because these endophytes can spread contagiously. Under this scenario, Epichloë hosts should show a stronger correlation than Neotyphodium hosts, thus separating the alternative hypotheses.

\section{Methods}

Summary of the literature.-We identified 53 published studies with sufficient data on within or among population variation in endophyte frequency (Appendix 
A gives detail on study selection). We included data collected from herbarium specimens, fresh material, and germplasm (seed) banks, but used only those host species originally collected in their native habitats. We calculated two response variables: (1) the mean percentage of plants with the endophyte per population, using only those populations for which at least one plant had an endophyte, and (2) the percentage of populations for which at least one plant had an endophyte.

Plant collections: field survey.-We examined 1796 individual tillers, 3235 seeds, and 2244 seedlings, spanning 123 populations and 20 grass species. We collected live tillers and/or seeds from an average of 18.1 \pm 0.8 plants/population (mean $\pm \mathrm{SE}$; range $=5-45$; small samples reflected the small sizes of some populations). Appendix B gives information for each collection. We focused on regions where we are currently conducting endophyte experiments.

Endophyte detection: field survey.-For field-collected adult tillers, we removed thin sections of leaf sheath, stained with an aniline blue solution (Clark et al. 1983), and scored at $100-400 \times$ on a light microscope (Leica Microsystems, Wetzlar, Germany). Positive endophyte detection was indicated by the presence of characteristic, long non-branching hyphae in the intercellular spaces (see Plate 1). We soaked seed tissue overnight in 5\% $\mathrm{NaOH}$, dissected under a stereoscope, and stained with an aniline blue solution (Bacon and White 1994). We stained greenhouse-grown seedlings from field collected seeds with rose bengal (Belanger 1996). We calculated the mean percentage of plants with the endophyte per population. Because we examined multiple tissue types (tillers, seeds, seedlings), we determined this mean both by taking the average percentage across tissue types and by taking the maximum percentage across tissue types. Analysis of these estimates produced qualitatively identical results (data not shown), and we report results for the average percentage across tissue types.

Prior studies have found that microscopic methods typically give similar results to tissue print immunoblot techniques or PCR-based methods of endophyte detection (e.g., Dombrowski et al. 2006, Trento et al. 2007). However, for two species, endophyte detection in tillers was much lower than for seeds (Cinna arundinacea, Elymus hystrix); this could indicate problems with detection or some degree of non-systemic endophyte infection (Bazely et al. 2007). Thus, microscopy may provide only a lower bound to endophyte frequency for some hosts.

Phylogenetic coverage.-We collected and compiled data for a total of 118 grass species, spanning eight of the 13 tribes in the subfamily Pooideae (Watson and Dallwitz 1992, Barker et al. 2001; details in Appendices A-C). While our coverage was phylogenetically broad, the large tribes (e.g., Poaeae) had low representation $(<5 \%$ of species, Appendix C), highlighting the need for more studies on endophyte frequencies in nature.
1. Are endophyte frequencies greater for asexual Neotyphodium than for contagious Epichloë?-We combined data from field surveys and published literature to test this question. Response variables were the mean endophyte frequency per population $(n=69$ grass species) and the percentage of populations with endophytes $(n=71)$. ANOVA models included the independent factors of endophyte genus and plant tribe (included to account for some of the variation due to host phylogenetic relatedness) (SAS Institute 2004). We could not additionally test for endophyte species effects because endophyte species are often unique to each host species (Clay and Schardl 2002), and many endophytes have not yet been identified to species (Appendices A and B; Moon et al. 2004). Residuals became normally distributed and variances homogenous following arcsine square-root transformation of both response variables.

In addition, we conducted a second, more-detailed, analysis, in which we classified endophytes to the best of our ability as Type I (exclusively horizontally transmitted), Type II (mixed vertical and horizontal transmission), or Type III (exclusively vertically transmitted) as designated by White (1988). Response variables were the mean endophyte frequency per population and the percentage of populations with endophytes. ANOVA models included the independent factors of endophyte type (I, II, or III) and plant tribe (SAS Institute 2004).

Because comparisons made across species risk pseudoreplication if phylogeny is ignored (Felsenstein 1985, Harvey and Pagel 1991), we also obtained phylogenetically independent contrasts for endophyte genus and both endophyte frequency estimates. We used published trees based on molecular data sets derived from chloroplast and nuclear gene sequences, nuclear and ribosomal ITS sequences, and AFLP markers (Gaut et al. 2000, Barker et al. 2001, Vergara and Bughrara 2003, Catalan et al. 2004, Torrecilla et al. 2004, Gillespie and Soreng 2005, Strauss et al. 2006). For each analysis, we assembled trees that included the subset of species for which endophyte data and phylogenetic information were available (mean endophyte frequency per population, $n=62$ species, percentage of populations $n=61$; Appendix C). We used Mesquite version 2.01 (Maddison and Maddison 2007). Because information on branch lengths was not available, we chose the best branch length estimator for each analysis following published recommendations (PDAP:PDTREE; Midford et al. 2005; see Appendix C). To examine relationships among phylogenetically independent trait values (i.e., the standardized contrast values), we used regression constrained through the origin (SAS Institute 2004) and report adjusted correlation coefficients (Garland et al. 1992). For a polytomous node, the degrees of freedom range from a minimum of 1 to a maximum of the number of species in the polytomy minus 2 (i.e., the number of contrasts minus 1; Midford et al. 2005). We present the full range of $P$ values for the correlations (maximum and minimum $\mathrm{df}$ for polytomies), because it 


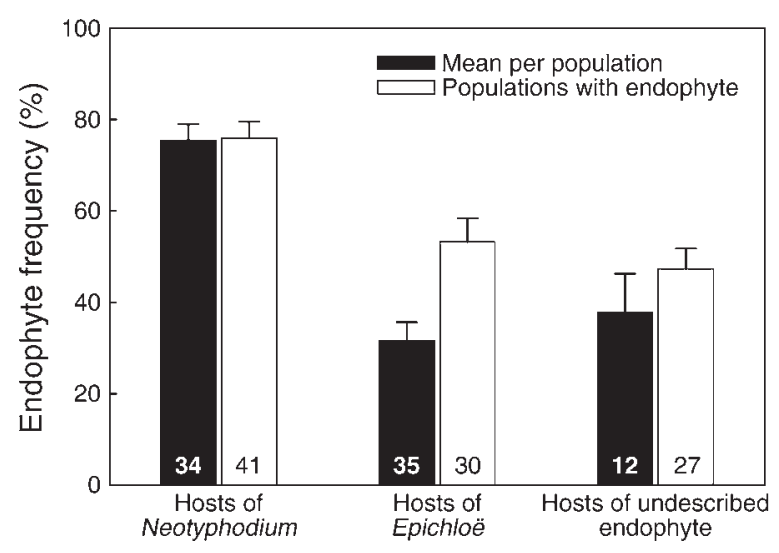

FIG. 1. Differences between hosts of Epichloë and Neotyphodium endophytes in the mean endophyte frequency per population and percentage of populations with the endophyte (data combined from the literature and our field surveys). Bars show means $+\mathrm{SE}$, and sample sizes (number of host species) are indicated on each bar. "Hosts of undescribed endophyte" indicates host species for which the endophyte genus remains unknown.

remains unclear whether polytomies are hard (indicating near simultaneous speciation) or soft (indicating lack of knowledge of the speciation sequence).

2. Is endophyte loss due to imperfect vertical transmission greater for Epichloë than for Neotyphodium?-For 44 populations spanning 11 host species, we calculated the proportional loss in endophyte frequency for each of two life history transitions: (1) tiller to seed and (2) seed to seedling. We did not track seeds from individual tillers of known endophyte status (but see Afkhami and Rudgers 2008); thus the tiller to seed transition may include both loss during tiller formation (i.e., some tillers escape infection by the endophyte) and loss during seed formation. In addition, for the seed to seedling transition, our prior work revealed that endophyte-infected seeds can have higher germination rates than endophyte-free seeds, resulting in greater endophyte frequencies for seedlings than for seeds (Afkhami and Rudgers 2008). Because we were interested in endophyte loss, for populations in which frequency increased during the transition, we scored proportional loss as zero. Species used for documenting imperfect transmission were Achnatherum eminens, Agrostis hyemalis, A. perennans, Cinna arundinacea, Elymus hystrix, E. virginicus, Festuca subverticillata, F. versuta, Poa alsodes, P. autumnalis, and P. sylvestris. All species had some degree of seed transmission of the endophyte (Appendix B). We used mixed model ANOVA (Proc MIXED, SAS Institute 2004), including the fixed factor of endophyte genus and the random effect of plant species (nested in endophyte genus). We did not apply phylogenetic corrections due to the small number of species represented (Epichloë, $n=4$ species; Neotyphodium, $n=7$ ).
3. Is variation in endophyte frequency greater among species than among populations within species, and does the amount of variation differ between endophyte genera?-We tested these questions for host species with data from more than five populations, including 32 species (representing seven tribes) with an average of $22 \pm$ 4 populations per species (mean \pm SE; range 6-116 populations). We applied ANOVA (SAS Institute 2004) on the arcsine square-root transformed mean endophyte frequency per population and included the random effects of host plant species (tested over variance within species, i.e., residual error) and plant tribe (tested over variance between plant species). We also used $F$ tests to ask whether the variance among Neotyphodium host populations (or species, $n=15$ ) was greater than the variance among Epichloë host populations (or species, $n=12$; hosts with unclassified endophytes, $n=5$, were not included in the comparison of endophyte genera). Only one species in this data set was Type I; therefore we did not conduct a more detailed analysis by life history strategy.

4. Does endophyte frequency correlate positively with host plant density?-In 22 populations spanning 19 species, we assessed local plant density by measuring nearest neighbor distances (Sutherland 1996) for an average of $43 \pm 6$ randomly selected plants per population and scored the percentage of plants with the endophyte (Appendix B). ANCOVA included endophyte genus, endophyte frequency, and endophyte genus $\times$ frequency to test whether endophyte frequency correlated positively with host plant density and whether the slope of this relationship differed for Epichloë vs. Neotyphodium hosts (SAS Institute 2004). This data set only included Type II and III endophytes. Endophyte frequency was arcsine square-root transformed to achieve normality of residuals and homogeneity of variances. In the analysis, three species (Elymus virginicus, Sphenopholis obtusata, S. nitida) were each represented by two populations. We treated these samples as independent because they were geographically distant (e.g., Indiana vs. Texas), but averaging the two populations gave similar results. We also tested for correlations between endophyte frequency and host density using phylogenetically independent contrasts, as described in question 1 (Appendix C).

\section{RESULTS}

1. Are endophyte frequencies greater for asexual Neotyphodium than for contagious Epichloë?-The mean endophyte frequency per population was $>130 \%$ higher for hosts of Neotyphodium than hosts of Epichloë (Fig. 1; $\left.F_{1,59}=27.0, P<0.0001\right)$. Similarly, for the percentage of populations with endophytes, hosts of Neotyphodium had $>40 \%$ higher endophyte frequencies than hosts of Epichloë (Fig. 1; $F_{1,62}=6.2, P=0.016$ ). In these analyses, we accounted for phylogeny by including plant tribe as a factor in the model, but tribe did not explain significant variation in endophyte frequency (mean endophyte frequency per population: $F_{7,59}=1.7, P=$ 
0.13 ; percentage of populations with endophytes: $F_{7,62}=$ 1.7, $P=0.14)$. For both response variables, higher endophyte frequencies for Neotyphodium remained after correcting the analysis for phylogenic relatedness using standardized independent contrasts. Mean endophyte frequency per population was higher for Neotyphodium than Epichlö $\left(r_{(60-50)}=0.64 ; 0.00001<P<0.001\right.$, ranges reflect df for alternative treatments of polytomies). The same pattern held for the percentage of populations with endophytes $\left(r_{(59-51)}=0.35,0.004<P\right.$ $<0.02)$. In addition, we found similar differences in frequency when endophytes were classified by life history type rather than by genus. Grasses with Type III endophytes (exclusively vertical transmission) had significantly higher mean endophyte frequencies per population than grasses with either Type I or Type II $\left(F_{2,54}=13.1, P<0.0001 ; \mathrm{I}, 26.5 \mathrm{a} \pm 8.3[n=9\right.$ (mean \pm $\mathrm{SE})]$; II, 33.0a \pm 4.8 [ $n=22]$; III, 74.7b $\pm 3.6[n=33]$; different superscript letters indicate significant differences via post hoc Tukey tests). Similarly, hosts of Type III endophytes had a greater percentage of populations with endophytes than hosts of Type II, with Type I (for which data were only available for seven species) not significantly different from either $\left(F_{2,55}=3.5, P=0.035\right.$; I, $49.8^{\mathrm{ab}} \pm 11.3[n=7] ;$ II, $56.8^{\mathrm{a}} \pm 5.8[n=18]$; III, $76.3^{\mathrm{b}}$ $\pm 4.1[n=41])$.

2. Is endophyte loss due to imperfect vertical transmission greater for Epichloë than for Neotyphodium?-If plants control vertical transmission, then loss of the endophyte during transmission to offspring may be higher for hosts of putatively less beneficial Epichlö species than for hosts of more beneficial Neotyphodium. During the transition from tiller to seed, loss of the endophyte was nearly $200 \%$ greater for hosts of Epichlö̈ (loss across species $=26.4 \% \pm 11.9 \%$, mean $\pm \mathrm{SE})$ than for hosts of Neotyphodium $(8.9 \% \pm 3.3 \%)\left(F_{1,9}=5.1, P=\right.$ $0.05)$. This loss may include both imperfect endophyte transmission among tillers within a plant as well as failure of the endophyte to grow into seeds. For the seed to seedling transition, loss of the endophyte was less common, was more variable among hosts, and did not significantly differ between endophyte genera (Epichlö̈, $9.5 \% \pm 8.0 \% ;$ Neotyphodium, $1.8 \% \pm 1.4 \% ; F_{1,6}=1.1, P$ $>0.3)$.

3. Is variation in endophyte frequency greater among species than among populations within species, and does the amount of variation differ between endophyte genera?-Variation in mean endophyte frequency per population was significantly greater among species than among populations $\left(F_{25,678}=18.2, P<0.0001\right)$, although the test for this difference was somewhat unbalanced because more data were available for species than for populations within species (Appendices A, B). Plant tribe did not explain significant variation in endophyte frequency $\left(F_{6,27}=2.08, P=0.09\right)$. Comparing endophyte genera, hosts of Neotyphodium (mean square $[\mathrm{MS}]=0.20)$ showed significantly greater variation among populations than did hosts of Epichloë $(\mathrm{MS}=$ $\left.0.15 ; F_{341,254}=1.3, P<0.006\right)$. There was no significant difference between endophyte genera in the amount of variation between species (Neotyphodium $\mathrm{MS}=3.09$, Epichloe $\left.\mathrm{MS}=2.35, F_{10,9}=1.3, P>0.3\right)$, although this test had small sample sizes (low power).

4. Does endophyte frequency correlate positively with host plant density? - Host density was positively correlated with endophyte frequency, but this relationship depended on the endophyte genus (endophyte genus $X$ endophyte frequency, $F_{1,19}=4.7, P=0.045$; endophyte frequency $F_{1,19}=0.2, P=0.6$, endophyte genus $F_{1,19}=$ 3.4, $P=0.08$ ). We expected a stronger correlation for Neotyphodium hosts if endophyte benefits were driving this relationship, and a stronger correlation for Epichlö hosts if these contagiously spread endophytes can attain higher frequencies when host plants are denser. The positive correlation was only significant for hosts of Epichloë (Fig. 2), consistent with the latter hypothesis. The same patterns held for standardized phylogenetically independent contrasts $\left(\right.$ Epichloë $r_{(9)}=0.73, P=$ 0.04 ; Neotyphodium $\left.r_{(7)}=-0.19, P=0.6\right)$.

\section{Discussion}

For natural host populations, we found that the mode of endophyte transmission was strongly associated with variation in endophyte frequency. Across 118 host species, endophyte frequencies were $40-130 \%$ higher for hosts of exclusively vertically transmitted Neotyphodium (Type III) endophytes than for hosts of mixed and horizontally transmitted Epichloë endophytes (Types I and II; White 1988). This pattern is consistent with the expectation of greater benefits conferred by Neotyphodium symbionts, for which the only documented means of transmission is through successful host reproduction (Schardl et al. 2004). Prior research showed that herbivore-deterrent alkaloids were more common in hosts of exclusively vertically transmitted endophytes (seven out of nine species examined had detectable alkaloids) compared to hosts of horizontally transmitted endophytes (three out of 11 species; Leuchtmann et al. 2000), which further supports a difference in the beneficial nature of the two endophyte groups. When endophyte species identifications and phylogenies become more resolved, it will be interesting to additionally account for the phylogenetic relatedness among endophytes, particularly as many of the Neotyphodium species are more closely related to Epichloë species than to other Neotyphodium (Moon et al. 2004). Finally, within the genus Epichloë, species can vary considerably in rates of vertical transmission, with some species (e.g., E. glyceriae, E. typhina) completely lacking vertical transmission, and others (e.g., Epichloë elymi in some Elymus spp.), rarely spread contagiously. Here, we have classified endophytes coarsely, by genus or life history type, potentially masking significant variation within Epichlö̈. A finer resolution of the relationship between transmission mode and endophyte frequency will require detailed observations on the many natural 


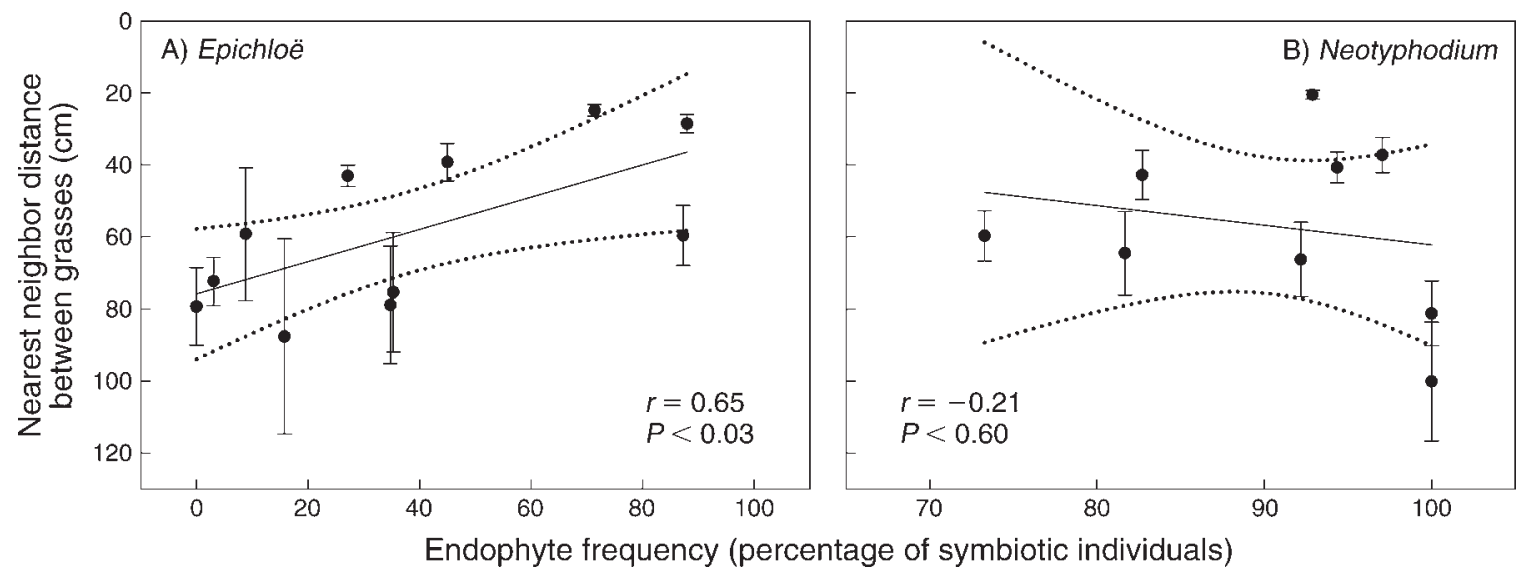

FIG. 2. Correlations between local plant density (nearest neighbor distance between conspecific grasses, mean \pm SE) and endophyte frequency (percentage of individual grasses with the endophyte) for hosts of (A) Epichloë and (B) Neotyphodium endophytes. Each point represents a grass species $\times$ location combination. Dotted lines show $95 \%$ confidence intervals around the slope. For Epichloë, the 11 samples were Agrostis hyemalis (Appendix B, population no. 9), Agrostis perennans (no. 11), Brachyelytrum erectum (no. 16), Elymus canadensis (no. 24), E. virginicus (nos. 53 and 55), E. hystrix (no. 31), Sphenopholis obtusata (nos. 118 and 123), and S. nitida (nos. 104 and 108). The correlation for Epichloë remained significant when populations within each host species were averaged (i.e., $n=8$ species; $r=0.71, P=0.047$ ). For Neotyphodium, the nine samples were Achnatherum eminens (no. 1), A. lobatum (no. 2), Cinna arundinacea (no. 20), Festuca ligulata (no. 56), F. subverticillata (no. 64), F. versuta (no. 70), Poa alsodes (no. 73), P. autumnalis (no. 93), and P. sylvestris (no. 97). Note the different $x$-axis scales between panels A and B.

populations of Epichloë for which the degree of vertical vs. horizontal transmission remains unknown.

Endophyte hosts may exert control over rates of symbiont transmission to offspring and restrict transmission of less beneficial, horizontally spread symbionts. Our surveys revealed that Epichloë hosts exhibited greater loss of the endophyte during a key life history transition, from tillers to seeds, relative to Neotyphodium hosts. In our data, this transition included both imperfect endophyte infection of tillers and loss during transmission to seeds, and distinguishing between these two mechanisms of loss could be achieved by tracking seeds from individual tillers of known endophyte status (Afkhami and Rudgers 2008). One possible proximate mechanism underlying imperfect transmission is a low concentration of endophyte hyphae in host tissues, which could affect the ability of endophytes to grow into seeds. Endophyte concentration can vary with plant and endophyte genotype as well as with environmental conditions (Spiering et al. 2005, Rasmussen et al. 2007, Mack and Rudgers 2008). Experiments that artificially inoculate the same host with endophytes that vary in the degree of horizontal transmission could help resolve the role of host plant control (e.g., Tintjer and Rudgers 2006).

The mode of transmission was also associated with the amount of variation in endophyte frequencies across populations. Hosts of Neotyphodium endophytes exhibited significantly more variation in endophyte frequency among populations than hosts of Epichlö̈. Because Neotyphodium apparently cannot spread among individuals or populations, founder effects may be stronger, and dramatic variation among host populations (e.g.,
$0 \%$ vs. $100 \%$ endophyte infected) may be more likely than for endophytes able to spread contagiously. It would be interesting to document the variability of symbiont frequency in other types of symbioses with both vertical and horizontal transmission (e.g., enteric bacteria, corals, Wolbachia).

Could the frequency of symbiosis explain why some host species are locally common and others are locally rare? Across host species, we did find a strong positive correlation between the local density of host plants and the proportion of plants with the endophyte. However, this relationship was only significant for hosts of Epichloe endophytes. This pattern is consistent with the alternative hypothesis that contagiously spread Epichloë can attain higher frequencies on hosts that are more dense or abundant in nature, rather than with the hypothesis that endophyte symbiosis promotes host abundance. However, Neotyphodium hosts had, overall, higher endophyte frequencies and a narrower range of variation in endophyte frequency across host species (73-100\%) than Epichloë hosts (0-88\%) (Fig. 2). Thus, low variation may explain the lack of a detectable relationship between local host abundance and endophyte frequency for Neotyphodium. Experimental manipulations of endophyte presence as well as host density would help to elucidate whether symbiosis with Neotyphodium can increase the local abundance of hosts or whether high host densities can increase the frequency of Epichloë symbiosis.

Broad surveys across 118 species of grasses revealed that a trait intrinsic to the symbiosis - the mode of transmission - was strongly correlated with the distribution and abundance of fungal symbionts in nature. 

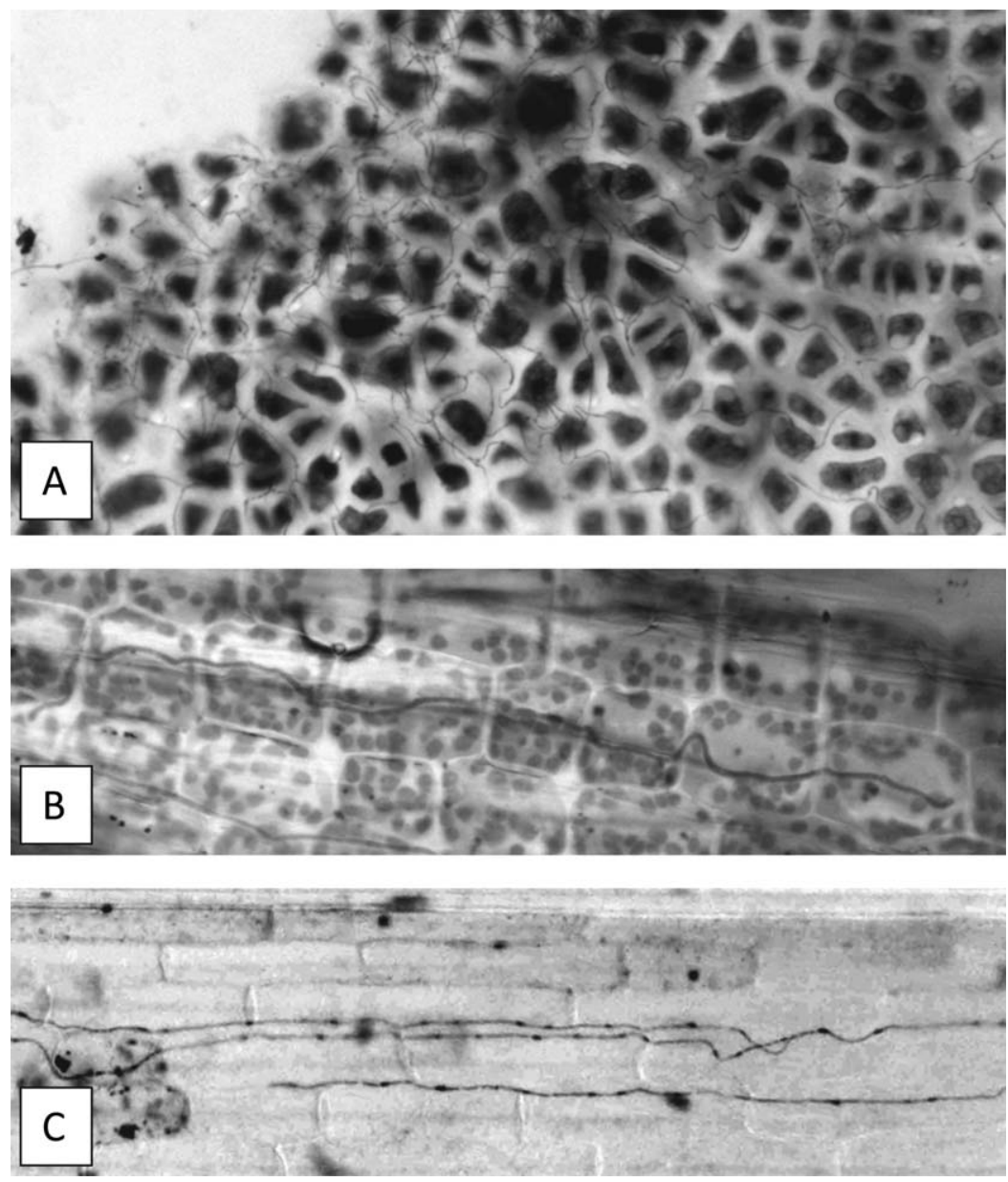

Plate 1. Fungal endophyte hyphae in (A) seed tissue of Poa sylvestris where hyphae are present in the aleurone layer, (B) seedling tissue of Poa alsodes where hyphae are present in the intercellular spaces, and (C) leaf sheath tissue of adult Poa sylvestris where hyphae are present in the intercellular spaces. All photographs taken at $200 \times$ on a light microscope. Photo credit: J. A. Rudgers.

We conclude that the evolutionary transition from horizontal transmission to exclusively vertical transmission may increase the frequency of symbiosis in nature, reduce the loss of the symbiont during vertical transmission, increase variation among host populations in symbiont frequency, and decouple the relationship between host density and symbiont frequency in local populations.

\section{ACKNOWLEDGMENTS}

Many thanks to K. Craven for assistance with endophyte identifications and to K. Craven, K. Whitney, and an anonymous reviewer for improvements to the manuscript. Rice undergraduates C. Baskett, O. Bartlett, K. Boles, K. Chu, F. Digilov, R. Howard, S. Kannadan, R. Sabouni, W. Valencia, and A. Vinze and helped with data collection. This work was funded by the Godwin Assistant Professorship and NSF-DEB \#054278 to J. A. Rudgers, and a Houston Rodeo Scholarship to M. E. Afkhami. We thank the Indiana University Research and Teaching Preserve, J. Sirotnak and Big Bend National Park, the City of Austin WQPL, the National Forests and Grasslands of Texas, and R. Thill and the Stephen F. Austin Experiment Forest for permissions to collect samples.

\section{Literature Cited}

Afkhami, M. E., and J. A. Rudgers. 2008. Symbiosis lost: imperfect vertical transmission of fungal endophytes in grasses. American Naturalist 172:405-416.

Bacon, C. W., and J. F. White, Jr. 1994. Stains, media, and procedures for analyzing endophytes. Pages $47-56$ in C. W. Bacon and J. F. White, Jr., editors. Biotechnology of endophytic fungi of grasses. CRC Press, Boca Raton, Florida, USA.

Bacon, C. W., and J. F. White, editors. 2000. Microbial endophytes. Marcel Dekker, New York, New York, USA.

Barker, N. P., et al. 2001. Phylogeny and subfamilial classification of the grasses (Poaceae). Annals of the Missouri Botanical Garden 88:373-457.

Bazely, D. R., J. P. Ball, M. Vicari, A. J. Tanentzap, M. Berenger, T. Rakocevic, and S. Koh. 2007. Broad-scale geographic patterns in the distribution of vertically-transmitted, asexual endophytes in four naturally-occurring grasses in Sweden. Ecography 30:367-374.

Belanger, F. C. 1996. A rapid seedling screening method for determination of fungal endophyte viability. Crop Science 36: 460-462.

Cahill, J. F., E. Elle, G. R. Smith, and B. H. Shore. 2008. Disruption of a belowground mutualism alters interactions 
between plants and their floral visitors. Ecology 89:17911801.

Catalan, P., P. Torrecilla, J. A. L. Rodriguez, and R. G. Olmstead. 2004. Phylogeny of the festucoid grasses of subtribe Loliinae and allies (Poeae, Pooideae) inferred from ITS and trnL-F sequences. Molecular Phylogenetics and Evolution 31:517-541.

Clark, E. M., J. F. White, and R. M. Patterson. 1983. Improved histochemical techniques for the detection of Acremonium coenophialum in tall fescue and methods of in vitro culture of the fungus. Journal of Microbial Methods 1:149-155.

Clay, K., and J. Holah. 1999. Fungal endophyte symbiosis and plant diversity in successional fields. Science 285:1742-1744.

Clay, K., J. Holah, and J. A. Rudgers. 2005. Herbivores cause a rapid increase in hereditary symbiosis and alter plant community composition. Proceedings of the National Academy of Sciences (USA) 102:12465-12470.

Clay, K., and C. Schardl. 2002. Evolutionary origins and ecological consequences of endophyte symbiosis with grasses. American Naturalist 160:S99-S127.

Dombrowski, J. E., J. C. Baldwin, M. D. Azevedo, and G. M. Banowetz. 2006. A sensitive PCR-based assay to detect Neotyphodium fungi in seed and plant tissue of tall fescue and ryegrass species. Crop Science 46:1064-1070.

Douglas, A. E. 1998. Host benefit and the evolution of specialization in symbiosis. Heredity 81:599-603.

Ewald, P. 1987. Transmission modes and evolution of the parasitism-mutualism continuum. Annals of the New York Academy of Sciences 503:295-306.

Faeth, S. H., and T. J. Sullivan. 2003. Mutualistic asexual endophytes in a native grass are usually parasitic. American Naturalist 161:310-325.

Felsenstein, J. 1985. Phylogenies and the comparative method. American Naturalist 125:1-15.

Fine, P. 1975. Vectors and vertical transmission: an epidemiological perspective. Annals of the New York Academy of Sciences 266:173-194.

Garland, T., Jr., P. H. Harvey, and A. R. Ives. 1992. Procedures for the analysis of comparative data using phylogenetically independent contrasts. Systematic Biology 41:18-32.

Gaut, B. S., L. P. Tredway, C. Kubik, R. L. Gaut, and W. Meyer. 2000. Phylogenetic relationships and genetic diversity among members of the Festuca-Lolium complex (Poaceae) based on ITS sequence data. Plant Systematics and Evolution 224:33-53.

Gehring, C. A., and T. G. Whitham. 2002. Mycorrhizaeherbivore interactions: population and community consequences. Pages 295-320 in M. van der Heijden and I. Sanders, editors. Mycorrhizal ecology. Springer-Verlag, Heidelberg, Germany.

Gillespie, L. J., and R. J. Soreng. 2005. A phylogenetic analysis of the bluegrass genus Poa based on cpDNA restriction site data. Systematic Botany 30:84-105.

Gonthier, D. J., T. J. Sullivan, K. L. Brown, B. Wurtzel, R. Lawal, K. VandenOever, Z. Buchan, and T. L. Bultman. 2008. Stroma-forming endophyte Epichloe glyceriaë provides wound-inducible herbivore resistance to its grass host. Oikos 117:629-633.

Gundel, P. E., W. B. Batista, M. Texeira, M. A. MartinezGhersa, M. Omacini, and C. M. Ghersa. 2008. Neotyphodium endophyte infection frequency in annual grass populations: relative importance of mutualism and transmission efficiency. Proceedings of the Royal Society B 275:897-905.

Harvey, P. H., and M. D. Pagel. 1991. The comparative method in evolutionary biology. Oxford University Press, Oxford, UK.

Johnson, N. C., J. H. Graham, and F. A. Smith. 1997. Functioning and mycorrhizal associations along the mutualism-parasitism continuum. New Phytologist 135:575-586.
Kannadan, S., and J. A. Rudgers. 2008. Endophyte symbiosis benefits a rare grass under low water availability. Functional Ecology 22:706-713.

Klironomos, J. N. 2002. Feedback with soil biota contributes to plant rarity and invasiveness in communities. Nature 417:6770.

Leuchtmann, A. 1992. Systematics, distribution, and host specificity of grass endophytes. Natural Toxins 1:150-162.

Leuchtmann, A., and K. Clay. 1989. Isozyme variation in the fungus Atkinsonella hypoxylon within and among populations of its host grasses. Canadian Journal of Botany 67: 2600-2607.

Leuchtmann, A., D. Schmidt, and L. P. Bush. 2000. Different levels of protective alkaloids in grasses with stroma-forming and seed-transmitted Epichloë/Neotyphodium endophytes. Journal of Chemical Ecology 26:1025-1036.

Mack, K. M. L., and J. A. Rudgers. 2008. Balancing multiple mutualists: asymmetric interactions among plants, arbuscular mycorrhizal fungi, and fungal endophytes. Oikos 117:310 320 .

Maddison, W. P., and D. R. Maddison. 2007. Mesquite: a modular system for evolutionary analysis. Version 2.5. $\langle$ http://mesquiteproject.org

Malinowski, D. P., D. P. Belesky, and G. C. Lewis. 2005. Abiotic stresses in endophytic grasses. Pages 187-199 in C. A. Roberts, C. P. West, and D. E. Spiers, editors. Neotyphodium in cool-season grasses. Blackwell Publishing, Ames, Iowa, USA.

Midford, P. E. T., T. Garland, Jr., and W. P. Maddison. 2005. PDAP Package of Mesquite. 〈http://mesquiteproject.org/ pdap_mesquite $>$

Moon, C. D., K. D. Craven, A. Leuchtmann, S. L. Clement, and C. L. Schardl. 2004. Prevalence of interspecific hybrids amongst asexual fungal endophytes of grasses. Molecular Ecology 13:1455-1467.

Muller, C. B., and J. Krauss. 2005. Symbiosis between grasses and asexual fungal endophytes. Current Opinion in Plant Biology 8:450-456.

Oliver, K. M., J. Campos, N. A. Moran, and M. S. Hunter. 2008. Population dynamics of defensive symbionts in aphids. Proceedings of the Royal Society B 275:293-299.

Omacini, M., E. J. Chaneton, C. M. Ghersa, and C. B. Muller. 2001. Symbiotic fungal endophytes control insect hostparasite interaction webs. Nature 409:78-81.

Pan, J. J., and K. Clay. 2002. Infection by the systemic fungus Epichloë glyceriae and clonal growth of its host grass Glyceria striata. Oikos 98:37-46.

Rasmussen, S., A. J. Parsons, S. Bassett, M. J. Christensen, D. E. Hume, L. J. Johnson, R. D. Johnson, W. R. Simpson, C. Stacke, C. R. Voisey, H. Xue, and J. A. Newman. 2007. High nitrogen supply and carbohydrate content reduce fungal endophyte and alkaloid concentration in Lolium perenne. New Phytologist 173:787-797.

Ravel, C., Y. Michalakis, and G. Charmet. 1997. The effect of imperfect transmission on the frequency of mutualistic seedborne endophytes in natural populations of grasses. Oikos 80:18-24.

Rudgers, J. A., and K. Clay. 2007. Endophyte symbiosis with tall fescue: How strong are the impacts on communities and ecosystems? Fungal Biology Reviews 21:107-124.

Rudgers, J. A., and K. Clay. 2008. An invasive plant-fungal mutualism reduces arthropod diversity. Ecology Letters 11: $831-840$.

Rudgers, J. A., J. Holah, S. P. Orr, and K. Clay. 2007. Forest succession suppressed by an introduced plant-fungal symbiosis. Ecology 88:18-25.

Rudgers, J. A., J. M. Koslow, and K. Clay. 2004. Endophytic fungi alter relationships between diversity and ecosystem properties. Ecology Letters 7:42-51. 
Rudgers, J. A., and A. L. Swafford. 2009. Benefits of a fungal endophyte in Elymus virginicus decline under drought stress. Basic and Applied Ecology 10:43-51.

Saikkonen, K., P. Lehtonen, M. Helander, J. Koricheva, and S. H. Faeth. 2006. Model systems in ecology: dissecting the endophyte-grass literature. Trends in Plant Science 11:428433.

SAS Institute. 2004. SAS version 9.1.3. SAS Institute, Cary, North Carolina, USA.

Schardl, C. L., A. Leuchtmann, and M. J. Spiering. 2004. Symbioses of grasses with seedborne fungal endophytes. Annual Review of Plant Biology 55:315-340.

Selosse, M. A., and C. L. Schardl. 2007. Fungal endophytes of grasses: hybrids rescued by vertical transmission? An evolutionary perspective. New Phytologist 173:452-458.

Shantz, H. L. 1954. The place of grasslands in the Earth's cover. Ecology 35:143-145.

Smith, S. E., and D. J. Read. 1997. Mycorrhizal symbiosis. Second edition. Academic Press, San Diego, California, USA.

Spiering, M. J., G. A. Lane, M. J. Christensen, and J. Schmid. 2005. Distribution of the fungal endophyte Neoyphodium lolii is not a major determinant of the distribution of fungal alkaloids in Lolium perenne plants. Phytochemistry 66:195202.

Strauss, S. Y., C. O. Webb, and N. Salamin. 2006. Exotic taxa less related to native species are more invasive. Proceedings of the National Academy of Sciences (USA) 103:5841-5845.

Sutherland, W. J. 1996. Ecological census techniques. Cambridge University Press, Cambridge, UK.

Tilman, D., D. Wedin, and J. Knops. 1996. Productivity and sustainability influenced by biodiversity in grassland ecosystems. Nature 379:718-720.
Tintjer, T., and J. A. Rudgers. 2006. Grass-herbivore interactions altered by strains of a native endophyte. New Phytologist 170:513-521.

Torrecilla, P., J. A. Lopez-Rodriguez, and P. Catalan. 2004. Phylogenetic relationships of Vulpia and related genera (Poeae, Poaceae) based on analysis of ITS and trnL-F sequences. Annals of the Missouri Botanical Garden 91:124158.

Trento, S., S. Elias, A. Garay, and J. Zavala. 2007. Comparison of endophyte detection in fescue and ryegrass seeds using an immunoblot assay and a microscopic method. Seed Science and Technology 35:65-74.

van der Heijden, M. G. A., J. N. Klironomos, M. Ursic, P. Moutoglis, R. Streitwolf-Engel, T. Boller, A. Wiemken, and I. R. Sanders. 1998. Mycorrhizal fungal diversity determines plant biodiversity, ecosystem variability and productivity. Nature 396:69-72.

Vergara, G. V., and S. S. Bughrara. 2003. AFLP analyses of genetic diversity in bentgrass. Crop Science 43:2162-2171.

Watson, L., and M. J. Dallwitz. 1992 onward. Grass genera of the world: descriptions, illustrations, identification, and information retrieval; including synonyms, morphology, anatomy, physiology, phytochemistry, cytology, classification, pathogens, world and local distribution, and references. $\langle$ http://delta-intkey.com/grass/>

Werren, J. H., and S. L. O’Neill. 1997. Influential passengers: inherited microorganisms and arthropod reproduction. Oxford University Press, Oxford, UK.

White, J. F., Jr. 1988. Endophyte-host associations in forage grasses: XI. A proposal concerning origin and evolution. Mycologia 80:442-446.

\section{APPENDIX A}

Data compiled from published studies on the frequency of symbiosis with Neotyphodium/Epichloë endophytes for 226 populations of host grass species (Ecological Archives E090-104-A1).

\section{APPENDIX B}

Field survey data on the frequency of symbiosis with Neotyphodium/Epichloë endophytes for 123 populations of host grass species (Ecological Archives E090-104-A2).

\section{APPENDIX C}

Tree used for comparison of mean endophyte frequency per population for grass hosts of Neotyphodium vs. grass hosts of Epichloë (Ecological Archives E090-104-A3).

\section{APPENDIX D}

Tree used for comparison of percentage of populations with the endophyte for grass hosts of Neotyphodium vs. grass hosts of Epichloë (Ecological Archives E090-104-A4).

\section{APPENDIX E}

Tree used for the analysis of correlation between local density and endophyte frequency for grass hosts of Epichloë (Ecological Archives E090-104-A5).

\section{APPENDIX F}

Tree used for the analysis of correlation between local density and endophyte frequency for grass hosts of Neotyphodium (Ecological Archives E090-104-A6). 